\title{
Impact of health service provision on mothers and infants in a rural village in North West Frontier Province, Pakistan
}

\author{
Christine A Northrop-Clewes ${ }^{1}$, , Nisar Ahmad ${ }^{2}$, Parvez I Paracha ${ }^{3}$ and \\ David I Thurnham ", \\ 1. Northern Ireland Centre for Diet and Health, University of Ulster, Coleraine, Northern Ireland BT52 \\ 1SA, UK: ${ }^{2}$ Pakistan Medical Research Council, Health Services Research Centre, Lady Reading \\ Hospital, Peshawar, NWFP, Pakistan: ${ }^{3}$ Department of Human Nutrition, Agricultural University, \\ Peshawar, NWFP, Pakistan
}

Submitied 26 October 1997: Accepted 15 December 1997

\begin{abstract}
Objective: The objective of this paper is to examine the impact of the Health Service Research Project of the Pakistan Medical Research Council (PMRC) on mothers and infants in Budhni village, North West Frontier Province (NWFP), Pakistan.

Methods: Information from the PMRC records on the socioeconomic and demographic situation over the last 10 years and anthropometric measurements made on all infants from 1986-96 were collected and analysed.

Results: The demographic data showed a number of changes, namely a reduction in birth rate and improvements in perinatal, neonatal, infant and child mortality rates. Literacy in the village was poor (27 and 39\% literate in 1986 and 1996, respectively) and female literacy showed no improvement (14\%). Improvements in sanitation and in the water supply introduced by the PMRC had limited success, as clean water was subsequently contaminated by unclean hands and utensils, and $50 \%$ of the population continued to use open fields for sanitation. In 1986 only $27 \%$ of children 0-5 years were vaccinated, but by $1996,96 \%$ of children had completed polio, diphtheria/pertussis/tetanus (DPT) and bacille Calmette-Guérin (BCG) vaccination programmes and $95 \%$ of women of child-bearing age were vaccinated against tetanus. Protection against tetanus reduced neonatal deaths and from 1993 onwards there have been no further cases.

Anthropometric data for the period 1986-96 for infants (0-24 months) showed that at birth the majority of infants were close to the 50th National Centre for Health Statistics (NCHS) centile for weight and length, and only $5 \%$ of birth-weights were less than $2.5 \mathrm{~kg}$. Growth charts showed faltering in length and weight and by 24-months length in both boys and girls was below the 3rd NCHS centile and weights were just above.

Conclusions: Reductions in child mortality have occurred over the period 1986-96. However, the slow progress in adopting hygienic practices, despite health education, and the low literacy rates, particularly in women, may hamper continued improvement.
\end{abstract}

\section{Keywords Rural Pakiston health services Infont growth Nutrition and health education}

\section{Background}

Pakistan is predominantly a rural Third World country with a high under- 5 child mortality rate of 137 per $1000^{1}$ and a high maternal mortality rate of 600 per 100,000 live births ${ }^{2}$. Malnutrition in women and children is widespread, with $50 \%$ of children under- 5 stunted. Pakistan has a high population growth rate $(3.1 \%$ per year) and the poor health status of many of its people requires extensive health-care services ${ }^{3}$. However, there is a lack of access to health care and this is one of the most important reasons for the poor health status, most particularly of the women and children. In addition, because of cultural restraints, it is preferred to have female health professionals to care for women, but such people are in short supply as education for women is very limited.

In 1977 the World Health Organization (WHO) Advisory Committee on Medical Research (ACMR) recognized the importance of the contribution of research to the organization and administration of the health system. In 1978 the ACMR appointed a 
subcommittee to determine the most important factors for health system research. In Pakistan the importance of health system research was recognized and a Data Generation Cell for Health Planning was established in Islamabad. In 1979 the administrative control of this data collection was transferred to the Pakistan Medical Research Council (PMRC) and the first health service research project was started in the Attock District of Punjab. In 1984 the PMRC decided to offer health service research projects to two other areas: Peshawar, North West Frontier Province (NWFP), a rural community, and Karachi, the capital and an urban area.

Following the sanctioning of the Peshawar rural project, the criteria for selection of the village areas were established: (a) a village population of 1000-5000 living within a radius of $15-30 \mathrm{~km}$ of Peshawar; (b) there should be no government-sponsored health facility or qualified doctor practising in the village; and (c) accommodation for the health centre should be available within the village itself. Two villages fulfilled the criteria and in April 1985 the first health centre was opened in a village called Tarai, and the second centre at Budhni was opened in March 1986. Unfortunately, the Tarai health centre was later closed because funding was not available.

The village of Budhni is about $25 \mathrm{~km}$ from the PMRC Research Centre in Peshawar. The population of the village in 1986 was 4215 , with most living in kucha mud houses (i.e. houses constructed from mud and bricks). There was no proper sanitation, drainage system or piped water, though most houses had electricity. The nearest government health facility was a basic health unit $5 \mathrm{~km}$ away. One room was rented in the centre of the village for the health centre and this was partitioned into sections to provide a reception area, an immunization room, an antenatal and well-baby clinic and a diagnostic clinic. A medical officer, six lady health visitors (LHV) and two male paramedics, staff the health centre. When the medical officer is not at the clinic, the LHV sees the women and children, while the paramedics attend to male patients. Simple treatments for fevers, diarrhoea, coughs, colds, eye infections and worm infestations are provided on the basis of symptoms. More serious medical conditions are referred to the hospital in Peshawar. There is no charge for medicine. In addition, two traditional birth attendants (TBA) were recruited and trained by the NWFP Health Department. The TBA liaise with the villagers providing information on births and deaths in the community as well as acting as midwives.

The objectives of the health services project were (a) to generate data on the prevalence of disease within the population each year; (b) to test the impact of some interventions like immunization programmes, health education with reference to personal hygiene and feeding practices; (c) to evaluate different methods of community motivation in the utilization of the health services; and (d) to evolve an integrated approach to the control of health problems through co-operation and collaboration with other departments and agencies working in the rural/urban areas. The ultimate goal was to develop a model for rural health-care delivery.

In 1996 the opportunity arose to collate data collected by the PMRC on infant growth, morbidity and mortality, which had accrued mainly over the period 1986-96, with the objective of examining the impact of the PMRC health service research project on factors influencing the health of mothers and infants in Budhni. This report describes some of the findings.

\section{Methods}

\section{Developmental pbases of tbe bealtb-care project} The first phase of the project in 1986 was a door-todoor survey of the village to identify and number households. The second phase began in 1988 when the village was mapped, by dividing Budhni into nine blocks, each house within a block being given a more meaningful number, e.g. block A house 1 , so that every household was allocated to an address. In addition, in the second survey all houses which were adjacent to the blocks, but were omitted in the first survey, were now also given a number. As a result of mapping the village, blocks of 150-200 households were assigned to each LHV to visit at least once a month. The LHV collected demographic information on all households, which was kept in family folders and included births, deaths, obstetric and health problems, child growth, immunization and household details. Furthermore, separate registers were established to collect data on births, deaths, immunizations, neonatal care, medication, family planning and home visits. During the second phase, all pregnant and lactating women were asked to attend the health centre for a medical examination, to give them advice on their own nutrition and information on the care and feeding of their infants. Mothers were encouraged to visit the clinic on a regular basis and the LHV reinforced this at each household visit. TBA notified the LHV of births in the village. The LHV then visited the home of the new mother within 3 days of the birth. Infants were weighed and measured at birth and subsequently mothers were encouraged to bring their infants, at least at 3-monthly intervals, for anthropometric measurements. Length is measured using a simple length board while weight is measured using digital baby scales. Initial training in anthropometry was given to LHVs, but no subsequent checks were made on the accuracy of the measurements.

Oral rehydration treatment (ORT) to manage diarrhoea and dehydration, was introduced to the villagers in 1988 together with improvements in 
environmental sanitation and the provision of clean water to households. In the third phase, which is currently ongoing, the PMRC staff are monitoring the impact of the interventions. Monthly reports are being submitted to the PMRC Research Centre. The data are then monitored to determine disease patterns, mortality rate and causes of mortality.

\section{Data acquisition and analysis}

Information from PMRC records was obtained on the demographic situation over the last 10 years together with the changes in sanitation, improvements in water supply and the development of the immunization programme for mothers and infants.

All anthropometric data available for infants of Budhni village from 1986 to 1997 were collected from health cards using two portable computers and put onto spreadsheets in Microsoft Excel. The data was then transferred to the Statistical Package for Social Sciences (SPSS) for analysis. In addition, where available, information on infant morbidity and weaning instructions were also collated from the health cards. Unfortunately, the latter data were only irregularly recorded and were insufficient for analysis.

\section{Results}

\section{Demograpbic data}

The PMRC began the health service research project in Peshawar by a door-to-door survey of the village in 1986 , when the total number of families recorded in the village was 803 (Table 1). In 1988 a more scientific approach was made when the village was mapped; the addition of all houses adjacent to blocks, but missed in the first survey, resulted in an increase in the total number of families from 803 to 883 . The basic demographic information from each household is kept in a family folder and Table 1 summarizes the demographic changes in the village from 1986 to 1996. The total population over the 10-year period showed a $60 \%$ increase, with little change in the proportion in any particular age group; however, infant, neonatal, perinatal and child mortality were all reduced (see below). Furthermore, between 1994 and 1996, there was another large increase in the population due to the addition of a small village, Shahjee Dheri, adjacent to the Budhni health research project. Literacy rate in the village was poor in 1986 with only $27 \%$ of the population able to read and write and is now only $39 \% 10$ years later. Female literacy, however, showed no improvement between 1990 and 1996. Data were not available before 1990 .

\section{Sanitation and water supply}

In $1986,98 \%$ of households obtained their water from shallow open wells and only $2 \%$ used hand pumps. Sanitation was almost non-existent with $52 \%$ using open fields, $47 \%$ surface latrines and only $1 \%$ had pourflush latrines. In 1988 the village committee identified the need for clean drinking water and sanitation as a priority. At the instigation of the PMRC, the Public Health Engineering Department in NWFP in collaboration with the German donor agency DORSCH, installed approximately 260 hand-pump wells to provide clean water and more than 100 pour-flush latrines to improve sanitation. Water hand-pumps and latrines were also installed in each of the three village schools, a high school for boys and the two primary schools, one for girls and one for boys. However, in 1996 although there was an improvement in the number of pour-flush

Table 1 Socioeconomic and demographic data from Budhni village 1986-96

\begin{tabular}{lrrrrr}
\hline & 1986 & 1988 & 1990 & 1994 & 1996 \\
\hline Total population & 4215 & 5139 & 5440 & 6076 & 6867 \\
Number of families & 803 & 883 & 925 & 932 & 979 \\
\% Families living in one room & 58 & 57 & 55 & 53 & 44 \\
\% Population < 5 years & 18 & 18.5 & 19 & 19.5 & 20 \\
\% Population 5-14 years & NA & NA & 29 & 29.5 & 29 \\
\% Population > 60 years & 5 & 4.5 & 4.2 & 4.5 & 5 \\
Total births year -1 & 194 & 227 & 193 & 212 & 218 \\
Birth rate (per 1000) & 54 & 44 & 35 & 33 & 32 \\
Population growth rate (per 1000) & 40 & 36 & 32 & 25 & 26 \\
Infant mortality (per 1000) & 102 & 97 & 124 & 21 & 55 \\
Neonatal mortality (per 1000) & 78 & 70 & 62 & 38 & 23 \\
Perinatal mortality (per 1000) & 54 & 44 & 78 & 5 & 18 \\
Child mortality 1-5 years (per 1000) & 31 & 29 & 27 & 11 & 9 \\
Literacy rate (\%) & 27 & 30 & 34 & 37 & 39 \\
Female literacy rate (\%) & NA & NA & 13.5 & 14.5 & 14.5 \\
Water - open well (\%) & 98 & 97 & 51 & NA & 35 \\
Water - hand-pumps (\%) & 2 & 3 & 51 & NA & 65 \\
Sanitation - open fields (\%) & 52 & 52 & 50 & NA & 50 \\
Sanitation - latrine (\%) & 47 & 43 & 30 & NA & 28 \\
Sanitation - pour-flush latrine (\%) & 1 & 5 & 18 & NA & 21 \\
Sanitation - VIP latrine (\%) & 0 & 0 & 2 & NA & 1.5 \\
\hline
\end{tabular}

NA, data not available. 
Table 2 Birth weights and lengths of girls and boys from 1987 to 96

\begin{tabular}{|c|c|c|c|c|c|c|}
\hline & \multicolumn{2}{|c|}{ Birth weight (kg) } & \multirow[b]{2}{*}{$\begin{array}{l}\text { ANOVA } \\
P \text { value }\end{array}$} & \multicolumn{2}{|c|}{ Birth length (cm) } & \multirow[b]{2}{*}{$\begin{array}{l}\text { ANOVA } \\
P \text { value }\end{array}$} \\
\hline & $\begin{array}{l}\text { Females } \\
\text { mean }(S E)\end{array}$ & $\begin{array}{c}\text { Males } \\
\text { mean (SE) }\end{array}$ & & $\begin{array}{l}\text { Females } \\
\text { mean (SE) }\end{array}$ & $\begin{array}{c}\text { Males } \\
\text { mean (SE) }\end{array}$ & \\
\hline 1987 & $\begin{array}{c}3.18(0.065) \\
(n=99)\end{array}$ & $\begin{array}{c}3.25(0.056) \\
(n=104)\end{array}$ & NS & $\begin{array}{c}49.32(0.31) \\
(n=95)\end{array}$ & $\begin{array}{c}49.05(0.28) \\
(n=99)\end{array}$ & NS \\
\hline 1988 & $\begin{array}{c}2.96(0.048) \\
(n=102)\end{array}$ & $\begin{array}{c}2.92(0.041) \\
(n=130)\end{array}$ & NS & $\begin{array}{c}50.36(0.42) \\
(n=67)\end{array}$ & $\begin{array}{c}49.72(0.45) \\
(n=87)\end{array}$ & NS \\
\hline 1989 & $\begin{array}{c}3.35(0.068) \\
(n=98)\end{array}$ & $\begin{array}{c}3.48(0.055) \\
(n=112)\end{array}$ & NS & $\begin{array}{c}49.70(0.29) \\
(n=78)\end{array}$ & $\begin{array}{c}50.06(0.32) \\
(n=96)\end{array}$ & NS \\
\hline 1990 & $\begin{array}{c}3.16(0.051) \\
(n=113)\end{array}$ & $\begin{array}{c}3.12(0.054) \\
(n=114)\end{array}$ & NS & $\begin{array}{c}49.78(0.31) \\
(n=105)\end{array}$ & $\begin{array}{c}49.88(0.29) \\
(n=107)\end{array}$ & NS \\
\hline 1991 & $\begin{array}{c}3.12(0.048) \\
(n=126)\end{array}$ & $\begin{array}{c}3.33(0.058) \\
(n=109)\end{array}$ & $P=0.006$ & $\begin{array}{c}50.54(0.21) \\
(n=108)\end{array}$ & $\begin{array}{c}51.38(0.16) \\
(n=94)\end{array}$ & $P=0.002$ \\
\hline 1992 & $\begin{array}{c}3.18(0.041) \\
(n=9)\end{array}$ & $\begin{array}{c}3.30(0.115) \\
(n=12)\end{array}$ & & $\begin{array}{l}51.6 \\
\quad(n=1)\end{array}$ & $\begin{array}{c}51.47(0.14) \\
(n=7)\end{array}$ & \\
\hline 1993 & $\begin{array}{c}3.35(0.127) \\
(n=24)\end{array}$ & $\begin{array}{c}3.29(0.122) \\
(n=25)\end{array}$ & NS & $\begin{array}{c}49.77(0.81) \\
(n=24)\end{array}$ & $\begin{array}{c}49.88(0.77) \\
(n=25)\end{array}$ & NS \\
\hline 1994 & $\begin{array}{c}3.01(0.053) \\
(n=95)\end{array}$ & $\begin{array}{c}3.13(0.051) \\
(n=106)\end{array}$ & NS & $\begin{array}{c}49.36(0.25) \\
(n=95)\end{array}$ & $\begin{array}{c}49.71(0.21) \\
(n=105)\end{array}$ & NS \\
\hline 1995 & $\begin{array}{c}3.16(0.048) \\
(n=101)\end{array}$ & $\begin{array}{c}3.19(0.047) \\
(n=127)\end{array}$ & NS & $\begin{array}{c}49.44 \pm 0.23 \\
(n=94)\end{array}$ & $\begin{array}{c}50.16(0.19) \\
(n=124)\end{array}$ & $P=0.017$ \\
\hline 1996 & $\begin{array}{c}3.04(0.049) \\
(n=107)\end{array}$ & $\begin{array}{c}3.14(0.057) \\
(n=107)\end{array}$ & NS & $\begin{array}{c}50.09(0.38) \\
(n=105)\end{array}$ & $\begin{array}{c}49.89(0.20) \\
(n=106)\end{array}$ & NS \\
\hline
\end{tabular}

latrines, $50 \%$ of the population were still using open fields for sanitation (see Table 1). Other public works carried out included the filling of four ponds of dirty water in the village with earth in 1990, and the construction of an open, street-drainage system with bricks in 1992 by the Public Health Engineering Department.

\section{Growtb of infants}

Table 2 shows the mean birth weights and birth lengths for girls and boys separately from 1987 to 1996 . There were significant differences between girls and boys for both birth weight and birth length in $1991(P=0.006$ and 0.002 , respectively, ANOVA) and birth length in 1995 ( $P=0.017$ ANOVA). There were no significant differences between the sexes in birth weight or birth length for any other year. Birth weights in 1987, 1988, 1989 and 1993, of both sexes combined, were significantly different from those in $1994(P=0.001$, $0.01,0.01,0.001$, respectively, ANOVA followed by

Table 3 Average weights $(\mathrm{kg})$ and lengths $(\mathrm{cm})$ of Budhni infants from birth to 24 months of age (months) for the period $1987-96$

\begin{tabular}{|c|c|c|c|c|c|c|c|c|}
\hline \multirow[b]{2}{*}{ Age (months) } & \multicolumn{4}{|c|}{ Boys } & \multicolumn{4}{|c|}{ Girls } \\
\hline & No. & Weight (kg) & No. & Length $(\mathrm{cm})$ & No. & Weight (kg) & No. & Length $(\mathrm{cm})$ \\
\hline 0 & 946 & 3.19 & 850 & 49.99 & 874 & 3.13 & 772 & 49.82 \\
\hline 1 & 447 & 3.97 & 194 & 52.10 & 420 & 3.83 & 170 & 51.60 \\
\hline 2 & 361 & 4.78 & 196 & 54.29 & 357 & 4.59 & 191 & 53.75 \\
\hline 3 & 437 & 5.27 & 202 & 56.13 & 415 & 5.07 & 175 & 55.21 \\
\hline 4 & 337 & 6.08 & 174 & 58.91 & 319 & 5.74 & 141 & 57.53 \\
\hline 5 & 307 & 6.64 & 157 & 60.80 & 286 & 6.30 & 122 & 59.53 \\
\hline 6 & 377 & 6.83 & 144 & 61.53 & 335 & 6.58 & 122 & 61.00 \\
\hline 7 & 262 & 7.51 & 131 & 63.39 & 221 & 7.16 & 97 & 62.99 \\
\hline 8 & 233 & 7.92 & 124 & 64.53 & 233 & 7.58 & 109 & 64.32 \\
\hline 9 & 318 & 7.93 & 124 & 66.17 & 296 & 7.68 & 102 & 64.77 \\
\hline 10 & 199 & 8.46 & 100 & 66.11 & 189 & 8.12 & 91 & 66.00 \\
\hline 11 & 180 & 8.72 & 89 & 67.97 & 156 & 8.37 & 62 & 67.29 \\
\hline 12 & 258 & 8.71 & 97 & 68.94 & 212 & 8.47 & 66 & 67.99 \\
\hline 13 & 141 & 9.11 & 76 & 69.74 & 111 & 8.62 & 58 & 68.98 \\
\hline 14 & 135 & 9.45 & 77 & 70.96 & 112 & 8.90 & 56 & 69.89 \\
\hline 15 & 111 & 9.59 & 55 & 71.71 & 94 & 9.08 & 45 & 71.32 \\
\hline 16 & 114 & 9.77 & 58 & 72.95 & 88 & 9.29 & 34 & 71.56 \\
\hline 17 & 102 & 9.89 & 43 & 73.14 & 75 & 9.45 & 32 & 71.55 \\
\hline 18 & 91 & 9.91 & 30 & 74.03 & 67 & 9.53 & 25 & 72.36 \\
\hline 19 & 80 & 10.03 & 19 & 74.47 & 63 & 9.71 & 16 & 73.75 \\
\hline 20 & 65 & 10.07 & 14 & 74.71 & 52 & 9.91 & 20 & 72.65 \\
\hline 21 & 57 & 10.16 & 17 & 75.94 & 46 & 9.97 & 15 & 74.40 \\
\hline 22 & 60 & 10.40 & 14 & 76.89 & 48 & 10.03 & 14 & 71.28 \\
\hline 23 & 43 & 10.24 & 7 & 77.71 & 35 & 10.29 & 5 & 76.40 \\
\hline 24 & 37 & 10.40 & 6 & 80.58 & 39 & 10.22 & 6 & 78.67 \\
\hline
\end{tabular}


Bonferroni test), while those in 1988, 1992, 1994 and 1996 were significantly different from those of 1995 ( $P=0.01$, ANOVA followed by Bonferroni test). On average over the 10 -year period, approximately $5 \%$ of infants each year had birth weights less than $2.5 \mathrm{~kg}$ and this did not change.

Table 3 shows the total number of measurements of weights and lengths recorded for boys and girls between 1987 and 1996. The data show that a large proportion of babies were weighed at birth, but subsequent to this the numbers of infants brought to the clinic for anthropometric measurements dropped off, so that by 24 months only a small number of mothers were regularly attending the clinic. The data are used to construct Figs 1-4. Figures 1 and 2 show mean weight growth for boys and girls separately for the first 24 months of life from all data collected over the 10-year period. Boys are significantly heavier than girls at all time points $(P<0.01$, ANOVA). At birth, the weight of both boys and girls are slightly below the 50th centile National Centre for Health Statistics (NCHS) ${ }^{4}$. Weights for boys slowly fall away from the 50 th centile from 1 month of age and by 24 months are close to the 3rd centile. Weights for girls continue on a trajectory just below the 50th centile for the first 3 months, then gradually fall away to a point near to the 3rd centile by 24 months.

Length growth of boys and girls are shown separately in Figs 3 and 4. Boys are generally longer than girls but

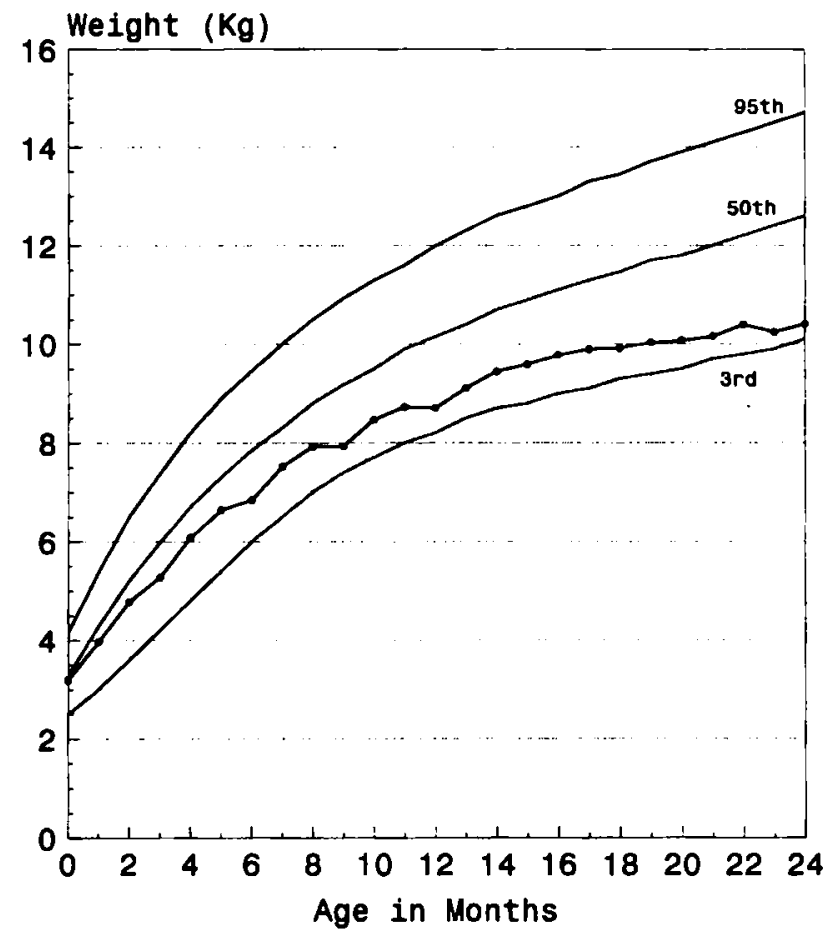

Fig. 1 Mean weight growth of boys (1987-96) from birth to 24 months of age compared to the 3rd, 50th and 95th NCHS reference standards

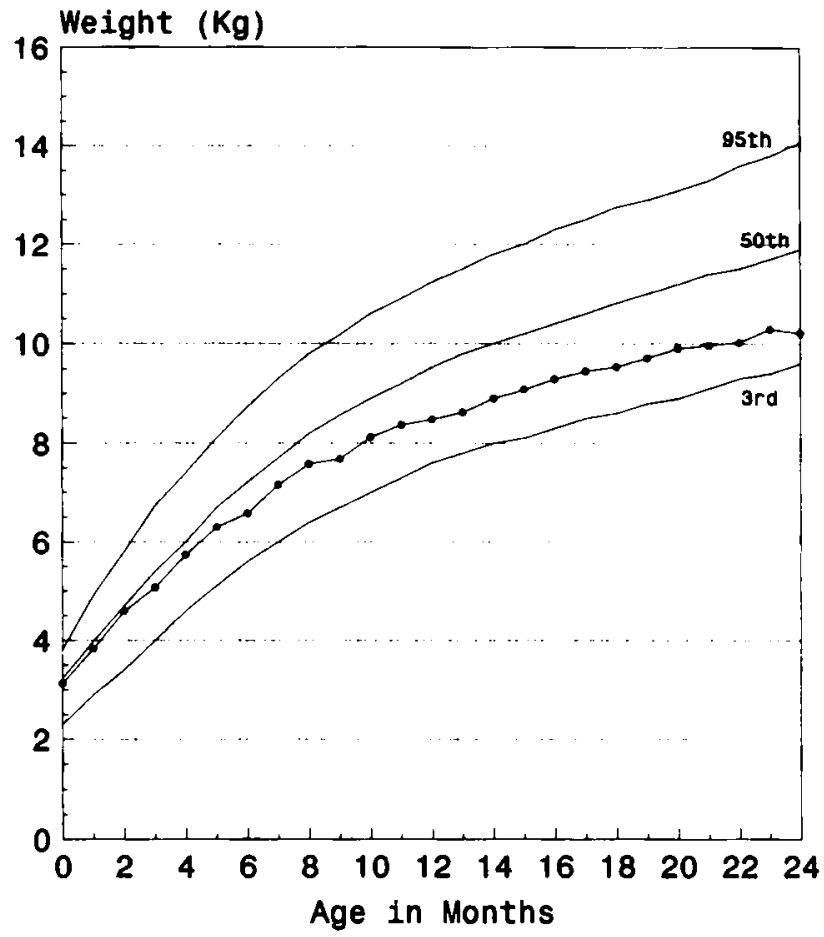

Fig. 2 Mean weight growth of girls (1987-96) from birth to 24 months of age compared to the 3rd, 50th and 95th NCHS reference standards

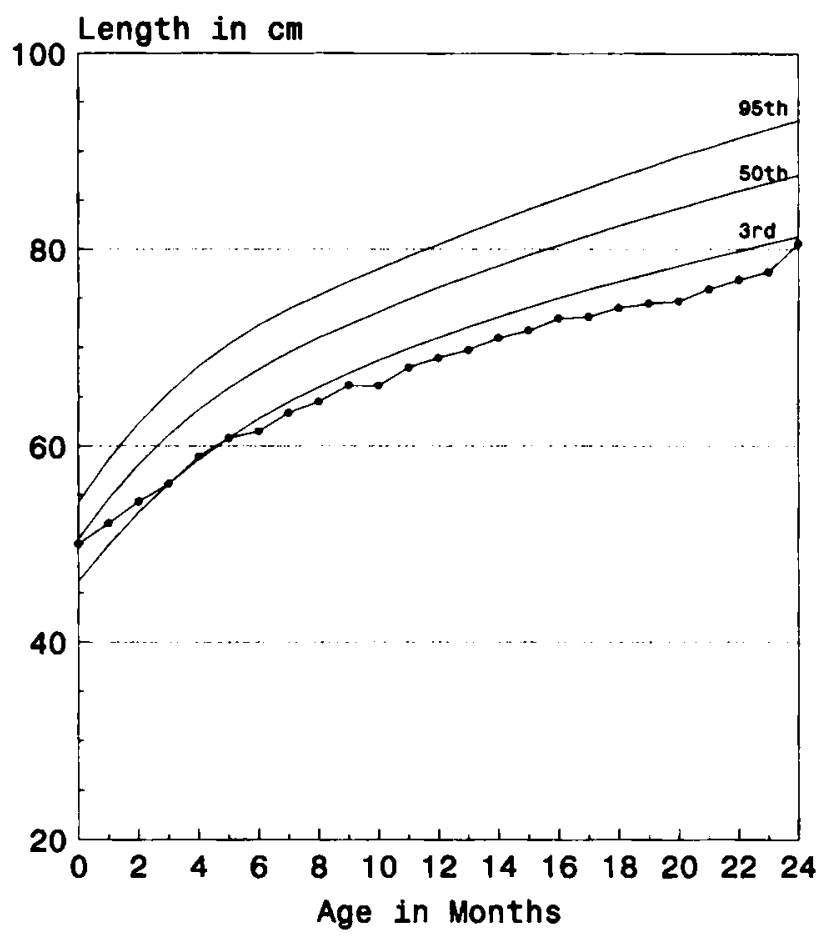

Fig. 3 Mean length growth of boys (1987-96) from birth to 24 months of age compared to the 3rd, 50th and 95th NCHS reference standards 


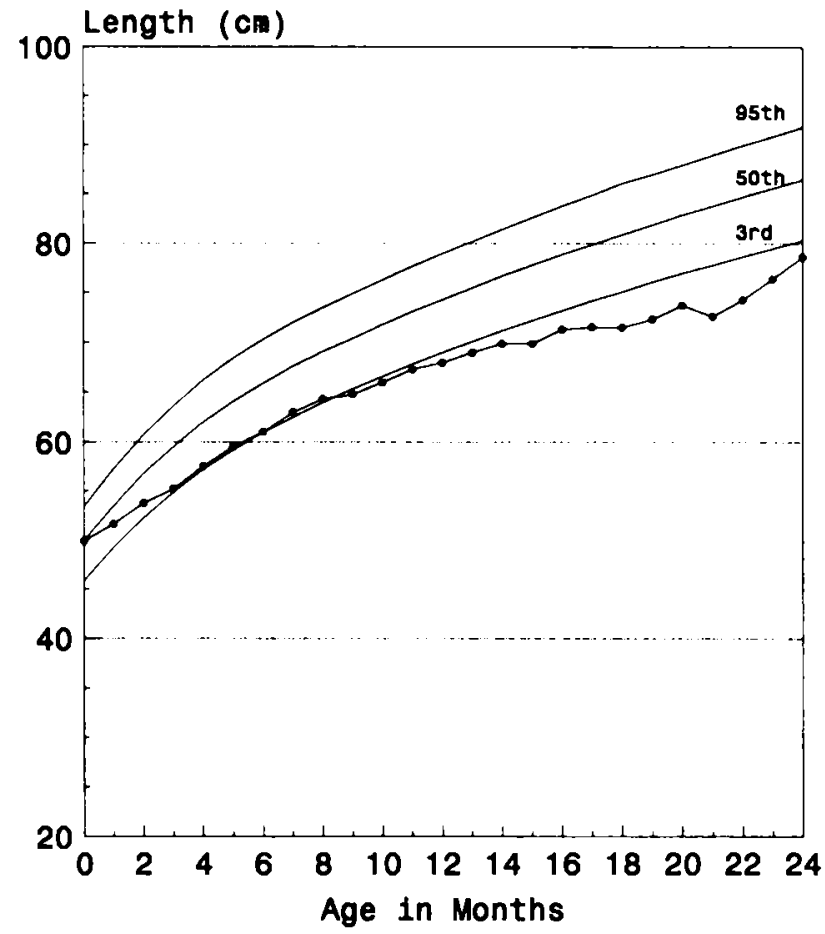

Flg. 4 Mean length growth of girls (1987-96) from birth to 24 months of age compared to the 3rd, 50th and 95th NCHS reference standards

these data were only significantly different at months 3 , $4,5,9$ and 22 ( $P<0.05$, ANOVA). Although both boys and girls have birth lengths on the 50th NCHS centile, beyond this age the trajectory falls away from this line and by 3 months the variable is on the 3rd NCHS centile. Length gain continues to fall below the 3rd centile from 5 months (boys) to 8 months (girls) not showing any improvement over the 24 months of data collection. The apparent increases in length gain at 21 months in girls and 23 months in boys are from a relatively small number of observations and may be an artefact (see Table 3 ).

\section{Financial support}

Table 4 shows the total number of attendances at the clinic for treatment and the budget available for drugs in Budhni. From 1989 to 1992 there were no funds available for the provision of medicine and money for staff salaries was at a minimum. As a result of the cutbacks in funding, there was little decline in outpatient attendance in 1989 compared with 1988, but by 1992 the attendance had declined to 637 visits. 1992 represented the nadir of health service provision in Budhni with only one LHV working per clinic day and no budget for medicine. The reduced number of staff is reflected in the lack of data collected in 1992 when information on birth measurements was only collected on 17 children compared with 200 or more in better years (see Table 3). In 1993 a small allocation of money was again available for medicine and all LHVs resumed normal work but it took a year before people began visiting the clinic in numbers similar to those prior to 1989.

\section{Immunization}

In 1986 only $27 \%$ of children aged $0-5$ years were vaccinated, but whether they completed a full vaccination programme is not known. Between 1986 and 1990 the immunization coverage for polio, tuberculosis (bacille Calmette-Guérin, BCG), diphtheria/pertussis/tetanus (DPT) was increased to $61 \%$ as a result of giving health education and motivation to the mothers. An intensive door-to-door immunization campaign followed which was very successful. By $1996,96.5 \%$ of children less than 5 years of age completed polio, DPT and BCG vaccination programmes and $95 \%$ of women of child-bearing age were vaccinated against tetanus. The protection against tetanus had a very positive effect in reducing neonatal deaths due to tetanus from 26 per 1000 in 1989 , when only $8 \%$ of women were immunized, to zero in 1996 . In 1994 a programme of immunization against measles was successfully started and has been continued except when the vaccine became unavailable in the second half of 1996.

\section{The role of women}

The average age of the mothers who gave birth between 1986 and 1996 was 31 years (median 30 years, range 15-49) with an average parity of 4.4 (median 4, range 1-14). In 1986, 690 married women were interviewed and asked about their attitude to family planning and family size, only $29 \%$ wished to have a small family. The reasons given were that $40 \%$ of husbands and $6 \%$ of mothers-in-law expected a large family, $41 \%$ of women said it was expected in their religion and $13 \%$ said it was their own wish to have a large number of children. Staff at the PMRC decided to target those mothers with three or more children to motivate them to use family planning for child spacing. Between 1989 and 1996, 343 women used the family planning programme and currently 192 are using the

Table 4 Outpatients (OPD) attendance at health centre and PMRC budget for medicine

\begin{tabular}{ccc}
\hline Years & OPD attendance & Budget for medicine (rupees) \\
\hline 1986 & 10,596 & 239,000 \\
1987 & 9043 & 16,000 \\
1988 & 5659 & 3000 \\
1989 & 6514 & Nil \\
1990 & 5022 & Nil \\
1991 & 2894 & Nil \\
1992 & 637 & Nil \\
1993 & 2396 & 10,000 \\
1994 & 5781 & 10,000 \\
1995 & 6548 & 10,000 \\
\hline
\end{tabular}


facilities and this use is perhaps reflected in the gradual reduction in birth rate (see Table 1 ).

The baseline survey in Budhni showed that women had no role in family income generation and they were therefore totally dependent on the male members of the family. An additional problem was the lack of literacy amongst the women (see Table 1). Through informal talks between the LHVs and the women, it became apparent that several women were interested in becoming literate and in learning some skills that would enable them to supplement the family income. The All-Pakistan Women's Association was approached by the PMRC and asked to help with this problem. Following discussions with the village elders, a village girl was selected and trained. A stitching centre was set up in the trained-girl's home and 20 young girls and women enrolled. As the village girl was also literate, she agreed to teach an adult literacy course to the women who attended the centre, books were provided by the Adult Literacy Department of the provincial government. The result at the end of the first year was encouraging, but unfortunately at the end of the second year the trainer moved to the city and the villagers could not find a replacement.

\section{Discussion}

Collectively, risks such as poor sanitation, insufficient and unsafe water supplies, poor personal hygiene, inadequate disposal of rubbish, indoor air pollution, crowded and inferior housing are associated with nearly $30 \%$ of the global burden of disease ${ }^{5}$. A combination of some of the risks described above are seen in socially deprived communities throughout the world, but in poor rural communities in developing countries, it is most likely to find all these health risks together.

Pakistan is predominantly an agricultural country with approximately $72 \%$ of the population living in rural areas, and because of limited resources, the per capita income is quite low with approximately $30 \%$ of the population living below the poverty line ${ }^{2}$. In general, the people in the towns are better off than those of rural areas, but unplanned urban growth has led to pockets of severe urban poverty ${ }^{2}$. In 1992 national figures indicated that in rural areas only $45 \%$ of the population had access to clean water and $10 \%$ to proper sanitation. Initial socioeconomic data collected from Budhni in 1986 (see Table 1) showed it to be a typical rural village with $98 \%$ of the population obtaining water from open wells and $99 \%$ using open fields or surface latrines for sanitation (see Table 1). The PMRC has helped to tackle the problems of sanitation and assisted in the installation of a clean water supply, by successfully installing 100 pour-flush latrines and 260 hand pumps for clean water in the village, but with limited apparent improvement in the adoption of hygienic practices. Water once collected from the wells, is stored in a variety of dubious containers to keep it cool and often contaminated by unclean hands or utensils. Sanitation was improved by the digging of pour-flush latrines instead of the surface latrines, but $50 \%$ of the population are still using the open fields. In addition, children seldom use latrines, squatting in the street or on a nearby rubbish dump, hence the problem of sanitation still has to be addressed. Unhygienic cooking practices, inappropriate disposal of rubbish, contaminated water and lack of personal hygiene contribute to the high incidence of diarrhoea and in particular to the health problems of the most vulnerable group, namely those children under 5 years of age. It is reported that $24 \%$ of all visits to the clinic by children under 5 years of age in Budhni during the period 198690 were for diarrhoea ${ }^{6}$. Therefore, in combination with a clean water supply and appropriate sanitation, health education should be given to mothers and children. Some effort in this direction is being made by the PMRC with the development of a health education model, but the effects of such changes in household practices are difficult to detect. Improvements in environmental conditions should affect growth and disease in infants. Hence the objective of the study was to examine the child anthropometric data for evidence of improvements over the last 10 years and to determine the current situation.

Approximately $5 \%$ of birth weights are low (less than $2.5 \mathrm{~kg}$ ) in Budhni, which is well within the UNICEF Nutrition Goal for the 1990s of less than $10 \%$. Low birth weight is an indicator of poor maternal nutritional status and the national average for low birth weight infants in Pakistan is $25 \%^{2}$. Therefore, Budhni is considerably better than the national average even though female literacy is only $14 \%$ and comparable with national figures. However, growth faltering soon after birth is very evident in Budhni, with length growth less than the 3rd NCHS centile by 6 months in boys and 10 months in girls. Weight hovered between the 50th and 3rd centiles, tending more towards the 3rd centile with increasing age. The pattern of growth of these Pakistani infants is similar to that of apparently healthy rural Gambian infants. In Gambian infants, growth was parallel to the 50th NCHS centile for the first 3 months, but subsequently both weight and length fell away from this trajectory, so that by 12 months both variables were close to the 5 th centile ${ }^{7}$. The Gambian study revealed that up to $43 \%$ of observed growth faltering could be explained on the basis of persistent abnormalities in the small bowel mucosa, as measured by the dual sugar permeability test. Whether such abnormalities are responsible for the growth deficits in the Pakistani children is currently not known. However, vitamin A status measured in infants in two 
villages approximately $20 \mathrm{~km}$ away was marginal ${ }^{8}$ with $65 \%$ of infants (mean age of 14 months) having plasma retinol $<0.7 \mu \mathrm{mol} \mathrm{l}^{-1}$. Vitamin $\mathrm{A}$ is necessary for growth and recent evidence also suggests that poor gut integrity is repaired by small regular doses of vitamin $A^{\text {? }}$.

The PMRC have tried to encourage mothers to bring their infants for weight and length measurements and are having increasing success, but as mentioned earlier, the changing of normal practices is a slow process. Continual assessment of infant growth at monthly or at least at 3-monthly intervals is necessary to be able to target infants at risk of malnutrition. However, as shown in Table 3 the number of infants older than 12 months of age taken to the clinic for anthropometric measurements drops off precipitously. The drop off in attendance is probably due to the patriarchal family system which exists in Pakistan in which women remain under the guardianship of men who prefer that their women do not leave the home. In addition, there are fewer length measurements than weight measurements (see Table 3 ) as the LHVs prefer to weigh infants rather than measuring lengths, as measuring the length of an older, stronger child, who does not wish to be measured, can be extremely difficult.

Food is distributed unevenly within the family. The man is considered to be 'the bread winner' in Pakistani society and so most food is served to the man and to the sons and the leftovers are eaten by the rest of the family irrespective of the increased requirements of pregnant and lactating women or growing daughters. Women pay less attention to their diet reserving milk, eggs, meat and other nutritious foods for the husband and older male children. In addition, superstitions have become established that many green vegetables, fruits, eggs and milk should be restricted during childhood, pregnancy and lactation due to fear of stomach cramps and gastroenteritis (P.I. Paracha, unpublished data). Nutrition education is important to alleviate unnecessary superstitions and to understand the nutritive value of foods. Health education is being provided by the LHV to the mothers with respect to breast feeding, weaning practices, immunization, personal hygiene, usefulness of ORT in infantile diarrhoea, care during delivery of the baby, care of the newborn, child nutrition and family planning. The information is reinforced by monthly visits to each household and by encouraging the mothers to attend the health centre where infants can be weighed and measured. These measures have had more success with younger mothers. At the health centre other methods of health education including colourful pictorial posters explain what types of nutritious foods should be eaten during pregnancy and lactation and portion sizes are illustrated. Unfortunately no data have been collected to evaluate whether such posters or other forms of education have been effective.
The components of a minimum clinical service include services to ensure pregnancy-related care, family planning services, tuberculosis control, control of sexually transmitted diseases (where appropriate) and care for the common serious illnesses of young children, i.e. diarrhoea, acute respiratory disease, measles and acute malnutrition. Immunization of children and women of child-bearing age had moderate success as a result of health education and motivation but it was only with the introduction of an intensive door-to-door campaign on immunization, that the target of $100 \%$ was achieved. The inability to persuade mothers to accept immunization until it was offered to women in their own homes, is a reflection of a society in which women reluctantly leave the family home because of cultural restraints.

In 1987 the Pakistan adult literacy rate was low with $36 \%$ of men and $15 \%$ of women (26\% overall) able to read and write ${ }^{10}$. The literacy rate in Budhni in 1986 was comparable to the national statistic with $27 \%$ of the population literate. Education is a problem in many Pakistani villages and this has been reflected in low literacy rates in men and women, but most especially in women. Parents are reluctant to send their sons to a school which is not in the centre of their own village and even more reluctant to send a daughter. Budhni has primary schools for girls and boys, but a high school for boys only. Girls are rarely educated at all and currently education to primary school level is the best that can be hoped for. Local governments need to legislate to expand basic education, most especially for girls as they are the mothers of the future. The ways in which mothers use information and financial resources shape the dietary, fertility, health care and other lifestyle choices and these have a powerful influence on the health of the other household members. Household decisions shape health but are constrained by the income and education of the family members ${ }^{5}$. Raising the educational standards and awareness of women will, in the long run, improve economic growth of the family and the community and promote good health.

\section{Acknowledgements}

The authors would like to thank the Wellcome Trust for a travel grant in support of this work. We would also like to thank all the staff of the Budhni Health Service Research Project for all their work in collecting and recording the data.

\section{References}

1 Grant J.P. The State of the World's Children. United Nations Childrens' Fund. New York: Oxford University, 1995, 5: 66.

2 UNICEF. Situation Analysis of Cbildren and Women in Pakistan. Pakistan: UNICEF, 1992. 
3 Majumdar B., Amarsi Y., Carpio B. Pakistan's community health workers. Canadian Nurse 1997; 93: 32-4.

4 National Center for Health Statistics. Growth charts. Rockville, MD: US Department of Health, Education and Welfare, Public Health Service, Health Resources Administration (HRA76-1120, 25 3), 1976.

5 World Development Report. International Bank for Reconstruction and Development/the World Bank, Washington, DC 1993.

6 Chavasse D., Ahmad N., Akhtar T. Scope for fly control as a diarrhoea intervention in Pakistan: a community perspective. Soc. Sci. Med. 1996; 8: 1289-94.

7 Lunn P.G., Northrop-Clewes C.A., Downes R.M. Intestinal permeability, mucosal injury and growth faltering in Gambian infants. lancet 1991; 338: 907-10.

8 Northrop-Clewes C.A., Paracha P.I., McLoon U., Thurnham D.I. Effect of improved vitamin A status on response to iron supplementation in Pakistani infants. Am. J. Clin. Nutr. 1996; 64: 694-9.

9 Northrop-Clewes C.A., McCullough F., Das B.S., Lunn P.G., Downes R.M., Thurnham D.I. Improvements in Vitamin A Intake Influence Gut Integrity in Infants. XVII IVACG Meeting Cairo, Egypt, 1997.

10 Kurian G.T., ed. Pakistan. In: Encyclopaedia of the Third World, third edition, Vol. ii, 1987. 